International Journal of Biology, Pharmacy and Allied Seiences (IJBPAS) 'A Bridge Botween Cabortory and Qendor'

WwW.ijbpas.com

\title{
IN VITRO EXAMINE OF RISPERIDONE IN DRUG TABLET DOSE STRUCTURE USING REVERSE PHASE FLUID CHROMATOGRAPHIC (RP-HPLC) STRATEGY
}

\section{ANITHA ${ }^{1}$, M. MANORANJINI ${ }^{2 *}$ AND K. PARAMESWARARAO ${ }^{3}$}

1, 2: Department of Chemistry, P. B. Siddartha College of Arts \& Sciences, Vijayawada, A.P, India

3: Department of Chemistry, Andhra Loyala College, Vijayawada, A.P, India

*Corresponding Author: E Mail: Dr. M. Manoranjini: dr.manoranjanimedikonda@gmail.com

Received $19^{\text {th }}$ Aug. 2021; Revised $20^{\text {th }}$ Sept. 2021; Accepted $29^{\text {th }}$ Oct. 2021; Available online $1^{\text {st }}$ Dec. 2021

https://doi.org/10.31032/IJBPAS/2021/10.12.2008

\begin{abstract}
The present investigation was to create and approve another reverse phase fluid chromatographic (RP-HPLC) strategy to measure in vitro examine of risperidone in drug tablet dose structure. The separation was performed on Inertsil ODS C-18 (150 x $4.6 \mathrm{~mm}, 5 \mu)$ molecule size section, and infusion volume was $10 \mu \mathrm{L}$ utilizing a UV 2301 Spectrophotometer to screen the identification at $260 \mathrm{~nm}$. The mobile phase comprised of methanol: $0.1 \%$ formic acid in the proportion 40:60\% $/ \mathrm{v}$, and the stream rate was kept up at $1.0 \mathrm{ml} / \mathrm{min}$. the technique was approved as far as reasonableness, linearity, exactness, accuracy, solidness, and affectability. Linearity was seen over the scope of focus $4.0-12.0 \mu \mathrm{g} / \mathrm{ml}$, and the correlation coefficient was found phenomenal $>0.9999$. The technique was exact and had relative standard deviations (\%RSD) under 2.0\%. Exactness was found in the scope of 99.90 to $101.7 \%$. The developed procedure was vigorous in various variable conditions and reproducible. This proposed technique can be utilized as quality control device for the assessment of risperidone in routine disintegration test investigation.
\end{abstract}

\section{Keywords: Risperidone, RP-HPLC, Validation}

\section{INTRODUCTION:}

Risperidone (The Merck Index, 2001; British

Pharmacopoeia, 2007; Tripathi KD, 2019)

(Figure 1). 3-[2-[4-(6-fluoro-1,2-benz-oxazol-

3-yl) piperidin-1-yl]ethyl]-2-methyl-6,7,8,9- tetra-hydro-pyrido [1,2-a]pyrimidin-4-one compound used for treatment certain mental/mood disorders (such as schizophrenia, bipolar disorder, irritability associated with 
autistic disorder). It is available in the local pharmacy under various brands i.e, Respidon (2.0mg, Torrent Pharmaceuticals), used in the treatment of schizophrenia.

Writing audit uncovered that there are not many logical strategies revealed for the examination of risperidone either independently or in mix with other dose forms (Bhavana A. Kokane, 2014; Suthar, AP.,2009; Ashour Safwan, et al., 2013; Alivelu Samala, et al., 2013;Sanka Krishna, et al., 2014; Cheng-tung chen, et al., 2015). Basing on this understanding there is a requirement for the improvement of another investigative strategy for the estimation of risperidone in pharmaceutical definition. The goal of the present research is to develop and validate a HPLC method for risperidone to be employed in routine analysis.

\section{MATERIAL AND METHODS:}

i. Instrumentation: HPLC framework PEAK LC 7000 furnished with isocratic HPLC PEAK 7000 conveyance framework, manual Rheodyne injector with a $10 \mu$ l circle switch (77251), logical column; Inertsil ODS C-18 (150 X 4.6 $\mathrm{mm}, 5 \mu$ ) with PEAK LC programming variant was utilized. UV 2301 Spectrophotometer was utilized to decide the frequency of most extreme absorbance and Electronic equilibrium DENVER (SI234) was utilized for gauging purpose.

ii. Chemicals and Solvents: The functioning standard medication of risperidone unadulterated was mercifully given as a talented sample by Doxis laboratories, India. Every one of the synthetic substances utilized like methanol, acetonitrile, water were of HPLC grade and were bought from Merck synthetic compounds private restricted, Mumbai, India. The promoted detailing brand Respidon (2.0mg of risperidone, Torrent Pharmaceuticals) was bought in nearby pharmacy.

iii. Preparation of working standard test arrangements: $100 \mathrm{mg}$ of unadulterated medication was gauged and moved (working standard) into a $100 \mathrm{ml}$ volumetric jar. The diluent methanol was added and sonicated to break up it totally and made sufficient with a similar solvent. Further $1.0 \mathrm{ml}$ of the above stock arrangement was pipetted into a $10 \mathrm{ml}$ volumetric flask and weakened sufficient with diluent. The substance were blended well and separated through Nylon channel paper. Working standard arrangements of risperidone in the obsession extent of 4.0$12 \mu \mathrm{g} / \mathrm{ml}$ was prepared from the above and injected to the chromatographic column.

iv. Preparation of sample arrangement: 10 detailing tablets of risperidone (Respidon (2.0mg, Torrent Pharmaceuticals) were squashed to a finely powdered material. Powder identical to $10 \mathrm{mg}$ of medication was taken in a $10 \mathrm{ml}$ volumetric cup containing $5.0 \mathrm{~mL}$ of mobile phase and 
was shaken to break down the medication and then separated through Nylon film channel paper. $1.0 \mathrm{ml}$ volume of the filtrate was acclimated to the imprint with a similar solvent to acquire grouping of $100 \mu \mathrm{g} / \mathrm{ml}$. The same procedure as described in working standard was used for the assay of sample respectively.

\section{RESULTS \& DISCUSSIONS:}

i. Method development: In order to make suitable procedure conditions for beneficial assessment of the current medicine different boundaries like mobile phase organization, stream rate, and $\mathrm{pH}$ were varied and improved condition was enlightened for assessment.

\section{OPTIMIZED METHOD}

Mobile Phase: Methanol: $0.1 \%$ formic acid in the proportion $40: 60 \% \mathrm{v} / \mathrm{v}$

Column: Inertsil (ODS 3v 150*4.6, 5mm)

Flow Rate: $1.0 \mathrm{ml} / \mathrm{min}$

Temperature: Ambient

Volume: $10 \mu 1$

Detector: $260 \mathrm{~nm}$

Diluent: Water: Methanol (50:50\%v/v))

Procedure: Inject $10 \mu \mathrm{L}$ of standard, sample into chromatographic system and measure the areas for the risperidone peak (Figure 2) and calculate the $\%$ assay by using the formula.

During starting preliminaries, top shape, goals and maintenance time were not in the line of agreeableness. At that point, further trails were finished by changing the mobile phase proportion, flow rate, $\mathrm{pH}$ and chromatographic section. A sharp peak with great symmetry of risperidone was acquired (Figure 2) during the trail when the mobile phase structure was methanol: $0.1 \%$ formic acid in the proportion $40: 60 \% \mathrm{v} / \mathrm{v}$ at a flow rate of $1.0 \mathrm{ml} / \mathrm{min}$ with UV detection at $260 \mathrm{~nm}$ individually.

ii. Method Validation: The proposed method was endorsed by (ICH2005) fitting for linearity, precision, precision, explicitness, a breaking point of discovery, farthest point of evaluation, force, toughness and system reasonableness.

System Suitability: System appropriateness test was finished by injecting on newly masterminded standard stock plans of risperidone and the system reasonableness parameters like objectives, following variable, theoretical plates and support time was considered and recorded.

Specificity: The distinction of the strategy was overseen by taking a gander at the measure and maintenance times when standard, clear and test arrangements were blended into the HPLC framework utilizing the improved conditions. A run season of $5.0 \mathrm{~min}$ was searched for a standard course of action and equivalent support times were looked for the tests also. Along these lines the made procedure was unequivocal for risperidone (Table 2).

Linearity: Working standard arrangements of risperidone in the obsession extent of 4.0$12 \mu \mathrm{g} / \mathrm{ml}$ were imbued into the 
chromatographic framework. Alignment twist of risperidone was obtained by plotting the peak area extent versus the associated groupings of medicine and the relationship coefficient was resolved. From the adjustment twist (Figure 3) it has been shown that the technique is immediate in the scope of 4.0$12 \mu \mathrm{g} / \mathrm{ml}$. The relapse condition of the line is seen to be $y=21185 x-88969$ and relationship coefficient is obtained as 0.9999.The particulars of the linearity results were given in Table 3.

Limit of discovery and Quantification: The LOD and LOQ estimations of risperidone was evaluated utilizing sign to commotion proportion and observed to be $0.0009 \mu \mathrm{g} / \mathrm{ml}$ and $0.003 \mu \mathrm{g} / \mathrm{ml}$ separately, which were assessed.

Precision: Repeatability of the method was checked by duplicate implantations of $8.0 \mu \mathrm{g} / \mathrm{ml}$ of for risperidone was done on various events on a similar day as intraday accuracy and on succeeding days as the intraday exactness assessments. The \%RSD regards apparently was 0.33 for intraday accuracy and the acknowledgments are given in Table 4 that exhibited the precision of the proposed methodology

Accuracy: Exactness was surveyed at three particular obsessions proportionate to 50, 100 and $150 \%$ of the unique fixing, by including a known proportion of risperidone standard to an illustration of known concentration and calculating the recovery of risperidon with
RSD (\%) and \% recovery for each obsession. The recoveries of the strategy given in Table 5 were seen to be in the extent of 99.0 to $101.7 \%$ which shows that the technique is significantly precise and suitable for the assessment of risperidone.

Robustness: The generosity study was performed by slight adjustment in stream pace of the mobile phase. Risperidone at $40 \mu \mathrm{g} / \mathrm{ml}$ center was inspected under these changed preliminary conditions. It was seen that there were no checked changes in chromatograms, which exhibited that the made technique was amazing in nature (Table 6).

Ruggedness: Roughness of the proposed framework was performed by utilizing six copy imbuements of standard and test approaches of risperidone which were planned and assessed by various expert on three different days and the attributes were bestowed also as rate relative standard deviation \% RSD appeared apparently was 0.67 , showing the procedure to be extreme.

Assessment of risperidone in pharmaceutical subtleties: Analysis of advanced tablets (Respidon - 2.0mg) was finished using the above said improved mobile phase and HPLC conditions. The \% medicine substance of tablets gotten by the proposed strategy for risperidone was seen to be $99.98 \%$ separately making the assessment of risperidone in estimations structures was precise inside the affirmation level of $95 \%$ to 100\%. The outcomes are given in Table 7. 


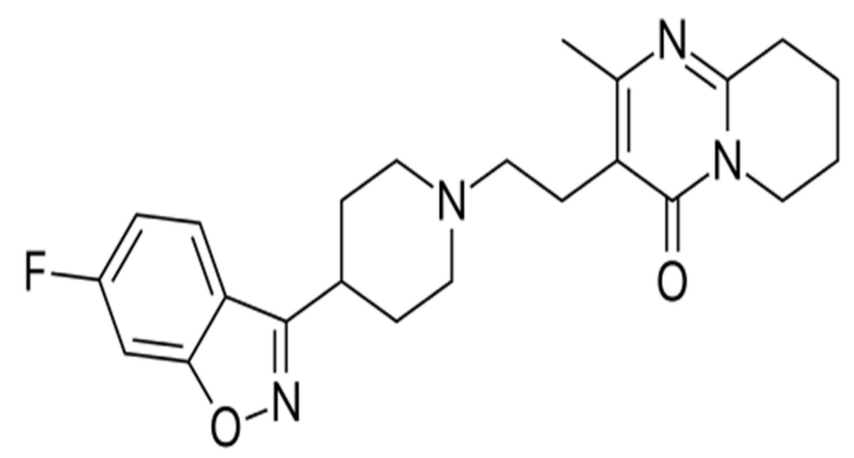

Figure 1: Structure of Risperidone

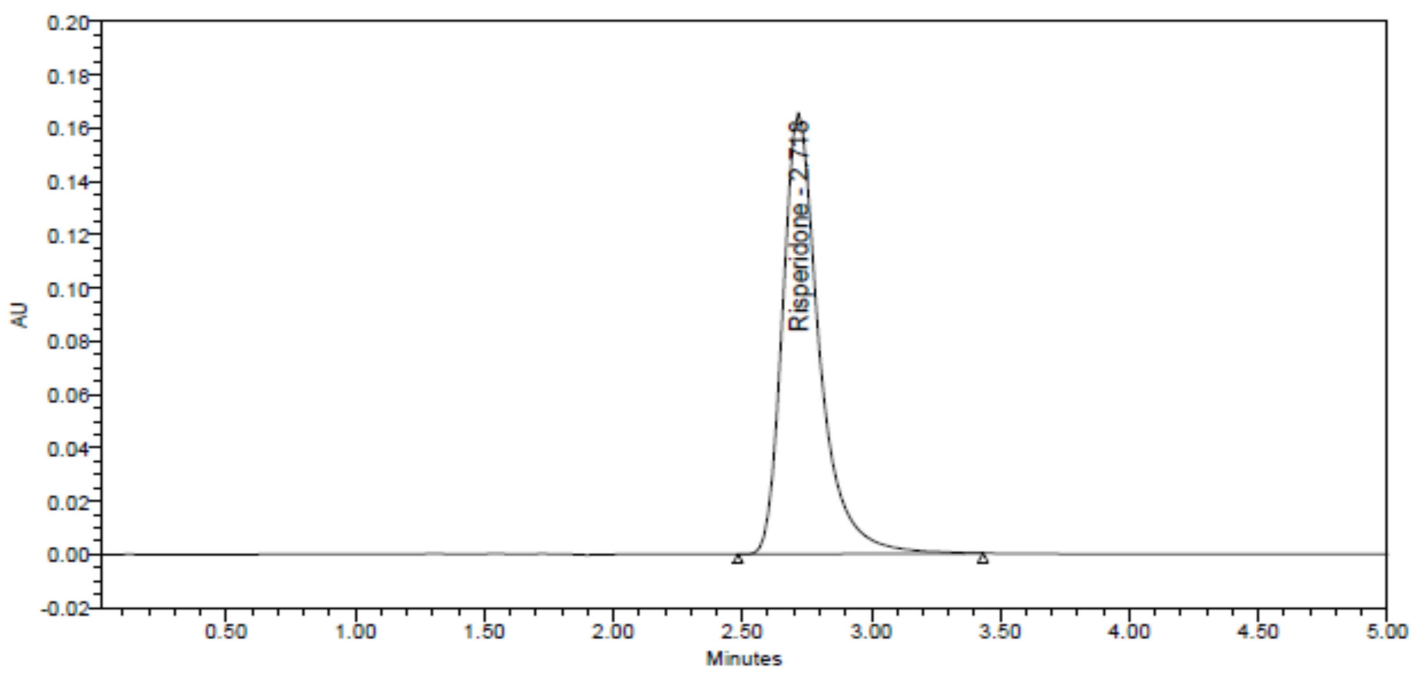

Figure 2: Chromatogram for optimized method

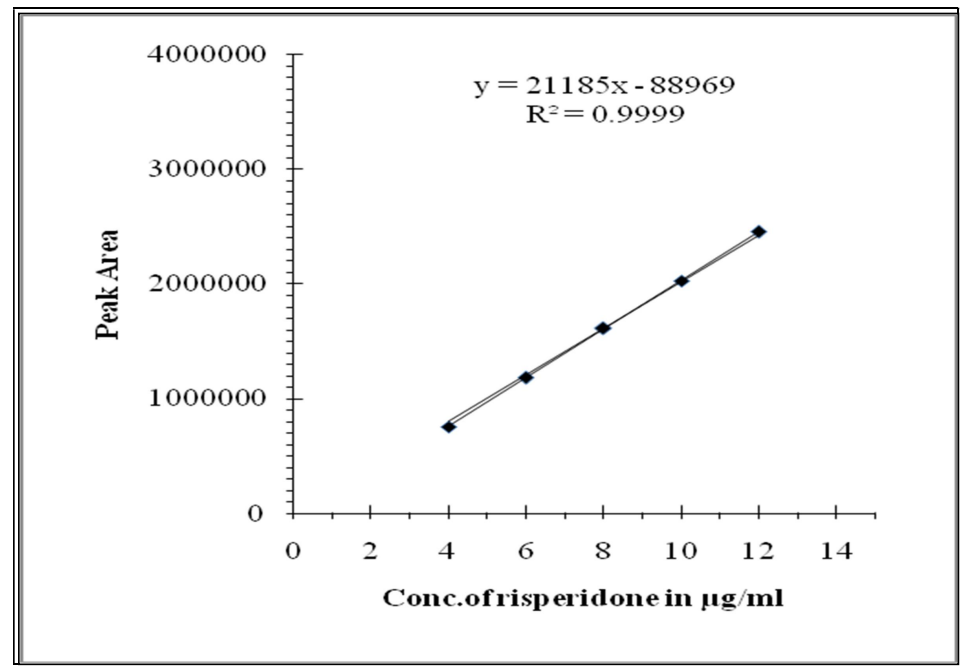

Figure 3: Linearity plot of risperidone

Table 1: System suitability data of Risperidone

\begin{tabular}{|c|c|}
\hline Parameter & Risperidone \\
\hline Retention time & $\mathbf{2 . 7 2 0}$ \\
\hline Theoretical plates & $\mathbf{1 9 4 4}$ \\
\hline Tailing factor & $\mathbf{1 . 4 0}$ \\
\hline \% RSD & $\mathbf{0 . 3 1}$ \\
\hline
\end{tabular}


Table 2: Specificity data for Risperidone

\begin{tabular}{|c|c|c|}
\hline S. No & Sample name & Rt \\
\hline 1 & Standard & 2.718 \\
\hline 2 & Sample & 2.715 \\
\hline 3 & Blank & - \\
\hline 4 & Placebo & - \\
\hline
\end{tabular}

Table 3: Linearity data for Risperidone

\begin{tabular}{|c|c|c|}
\hline S. No & level & Area \\
\hline 1. & $50(4.0 \mu \mathrm{g} / \mathrm{ml})$ & 757541 \\
\hline 2. & $75(6.0 \mu \mathrm{g} / \mathrm{ml})$ & 1181906 \\
\hline 3. & $100(8.0 \mu \mathrm{g} / \mathrm{ml})$ & 1609171 \\
\hline 4. & $125(10.0 \mu \mathrm{g} / \mathrm{ml})$ & 2027639 \\
\hline 5. & $150(12.0 \mu \mathrm{g} / \mathrm{ml})$ & 2453266 \\
\hline \multicolumn{2}{|c|}{ Correlation coefficient } & 0.9999 \\
\hline LOD & $0.0009 \mu \mathrm{g} / \mathrm{ml}$ \\
\hline
\end{tabular}

Table 4: Precision data for Risperidone

\begin{tabular}{|c|c|c|c|}
\hline S. No. & RT & Area & \%Assay \\
\hline Injection1 & 2.715 & 1597675 & 99.6 \\
\hline Injection 2 & 2.711 & 1594147 & 99.0 \\
\hline Injection 3 & 2.718 & 1593766 & 99.3 \\
\hline Injection 4 & 2.716 & 1592595 & 99.1 \\
\hline Injection 5 & 2.712 & 1588537 & 99.0 \\
\hline Injection 6 & 2.717 & 1597358 & 99.8 \\
\hline \multicolumn{3}{|c|}{ Mean } & 99.3 \\
\hline \multicolumn{3}{|c|}{ Std. Dev. } & 0.33 \\
\hline \multicolumn{3}{|c|}{ *\%RSD } & 0.33 \\
\hline
\end{tabular}

*Mean of six readings

Table 5: Accuracy data for risperidone

\begin{tabular}{|c|c|c|c|}
\hline S. No. & Accuracy level & Injections & \%recovery \\
\hline \multirow{3}{*}{1} & \multirow{3}{*}{$50 \%$} & 1 & 99.8 \\
\cline { 3 - 4 } & & 2 & 99.1 \\
\cline { 3 - 4 } & & 3 & 99.0 \\
\hline \multirow{3}{*}{2} & \multirow{3}{*}{$100 \%$} & 1 & 99.6 \\
\cline { 3 - 4 } & & 2 & 99.0 \\
\cline { 3 - 4 } 3 & \multirow{3}{*}{3} & 3 & 99.3 \\
\cline { 3 - 4 } & \multirow{3}{*}{$150 \%$} & 1 & 100.6 \\
\cline { 3 - 4 } & & 2 & 101.7 \\
\cline { 3 - 4 } & & 3 & 100.0 \\
\hline
\end{tabular}

Table 6: Robustness data for risperidone

\begin{tabular}{|c|c|c|c|}
\hline Parameter & RT & Theoretical plates & Asymmetry \\
\hline Decreased Flow Rate (0.9ml/Min) & 2.987 & $\mathbf{1 8 2 9 9 0 8}$ & 1.39 \\
\hline Increased Flow Rate (1.1ml/Min) & 2.473 & $\mathbf{1 8 2 9 9 0 8}$ & 1.39 \\
\hline
\end{tabular}

Table 7: Results of risperidone in formulations

\begin{tabular}{|c|c|c|c|c|}
\hline Drug & Brand & Dosage & Amount Found & \%Assay \\
\hline Risperidone & Respidon & $2.0 \mathrm{mg}$ & $99.98 \mathrm{mg}$ & $\mathbf{9 9 . 9 8}$ \\
\hline
\end{tabular}

\section{CONCLUSIONS:}

A supported, fundamental and precise, strength showing HPLC technique was made for the assessment of risperidoneee in pharmaceutical plans. Parcel of risperidone was cultivated on the Inertsil ODS C-18 column at an UV identification frequency of $260 \mathrm{~nm}$. In these conditions, the drug was eluted at a maintenance season of $2.720 \mathrm{~min}$ and the run was passed on up to $10 \mathrm{~min}$. A five-point alignment twist was inherent the center extent of $4.0-12 \mu \mathrm{g} / \mathrm{ml}$ with the relapse 
condition to be $y=21185 x-88969$ with a connection coefficient of 0.9999 independently giving the wide importance of the proposed RP-HPLC technique.

A very high \% recovery i.e., more than $100 \%$ was found in the recovery study that made the proposed strategy to be exact. Likewise, the proposed strategy was separated and was tracked down that the technique proposed can be related for the preliminary of the risperidone in a wide degree of center interests.

\section{ACKNOWLEDGMENTS}

The authors are gratified to the Department of Chemistry, P.B.Siddartha College of Arts \& Sciences, Vijayawada, AP, India for providing encouraging environment and facilities for research work.

\section{REFERENCES}

[1] Ashour Safwan Kattan Nuha (2013) Sensitive Method for the quantitative determination of risperidone in tablet dosage form by HPLC using chlordiazepoxide as internal standard Int. J. biomed. Sci, Vol 9 No 3 Pages 91-97.

[2] Alivelu Samala Santhosh Pawar Sowmya Manala et al (2013) Development and validation of RP-HPLC method for estimation of risperidone in tablet dosage form Research J. Pharm. and Tech Vol 6 No 6 Pages .659-661.

[3] British Pharmacopoeia (2007) Medicines and HealthcareProducts Regulatory
Agency (M.H.R.A).

[4] Bhavana A. Kokane., Dr.Jaiprakash V.Kokane. et al (2019) RP-HPLC method development and validation for estimation of risperidone in bulk $\&$ dosage forms Int. J. Pharm. Sci. Rev. Res Vol 54 No1 Page. 29-32.

[5] Cheng-tung chen, Cheng-wei cheng (2015) Development and validation of RP-UPLC method for determination of related substance in risperdal consta Chromatogr. Sep.Tech, Vol 6, Page 6.

[6] Sanka Krishna., Divan Prakash V (2014) Method development and validation for estimation of risperidone in novel liquid solid formulation by RP-HPLC Der Pharmacia letter Vol 6 No 1 Pages 166174.

[7] Suthar AP and Dubey SA (2009) Determination of risperidone and forced degradation behavior by HPLC in tablet dosage form. Int.J.pharma Tech res. Vol 1 No 3 Pages 568-574.

[8] The Merck Index (2001) Merck Research Laboratories, Division of Merck and company, $13^{\text {th }}$ ed, NJ, USA, Page 1627.

[9] Tripathi KD (2019) Essentials of Medical Pharmacology,5thed, Jaypee Brothers, Medical Publishers, New Delhi Pages 747, 150, 391, 394, 396, 397.

[10] International Conference on Harmonization ICH (2005) Validation of analytical procedures: methodology Q2 (R1). 